\title{
Journal News: Hartman and Spit's Research Work, Published in American Journal of Climate Change, Has Been Cited by Top Journal Nature Geoscience
}

\author{
AJCC Editorial Board
}

Copyright (C) 2016 by authors and Scientific Research Publishing Inc.

This work is licensed under the Creative Commons Attribution International License (CC BY). http://creativecommons.org/licenses/by/4.0/

(c) (i) Open Access

Capacity building is a key issue for the implementation of climate adaptation measures in urban planning processes. For successful capacity building, it is important to define the relevant stakeholders and tailor the adaptation strategies first to (the position of) these stakeholders and next to the specific urban conditions and issues. In addition, scientific insights and tools can be of assistance, and the use of climate maps can help to create a common language. Thomas Hartmann and Tejo Spit's research work on capacity building was published in American Journal of Climate Change, 3, 245-252, 2014 [1].

In June 2015, Thomas Hartmann and Tejo Spit's research work [1] was cited by Nature Geoscience as one of six important papers in the field of capacity building [2], in detail, please see:

http://www.nature.com/ngeo/journal/v8/n7/full/ngeo2465.html.

\section{References}

[1] Hartmann, T. and Spit, T. (2014) Capacity Building for the Integration of Climate Adaptation into Urban Planning Processes: The Dutch Experience. American Journal of Climate Change, 3, 245-252. http://dx.doi.org/10.4236/ajcc.2014.33023

[2] Hewitson, B. (2015) To Build Capacity, Build Confidence. Nature Geoscience, 8, 497-499. http://dx.doi.org/10.1038/ngeo2465 